This item was submitted to Loughborough's Research Repository by the author.

Items in Figshare are protected by copyright, with all rights reserved, unless otherwise indicated.

\title{
Bringing sex and chronic illness out of the closet: interviewing gay and bisexual men with diabetes
}

PLEASE CITE THE PUBLISHED VERSION

http://dx.doi.org/10.4135/9781526419163

PUBLISHER

(C) SAGE

VERSION

VoR (Version of Record)

\section{PUBLISHER STATEMENT}

This work is made available according to the conditions of the Creative Commons Attribution-NonCommercialNoDerivatives 4.0 International (CC BY-NC-ND 4.0) licence. Full details of this licence are available at: https://creativecommons.org/licenses/by-nc-nd/4.0/

\section{LICENCE}

CC BY-NC-ND 4.0

\section{REPOSITORY RECORD}

Jowett, Adam, and Elizabeth Peel. 2019. "Bringing Sex and Chronic Illness Out of the Closet: Interviewing Gay and Bisexual Men with Diabetes”. figshare. https://hdl.handle.net/2134/24543. 


\section{@SAGE researchmethods cases}

\section{Bringing Sex and Chronic Illness Out of the Closet: Interviewing Gay and Bisexual Men With Diabetes}

Contributors: Adam Jowett \& Elizabeth Peel

Pub. Date: 2017

Access Date: March 3, 2017

Academic Level: Advanced Undergraduate

Publishing Company: SAGE Publications Ltd

City: London

Online ISBN: 9781526419163

DOI: http://dx.doi.org/10.4135/9781526419163

(C2017 SAGE Publications Ltd. All Rights Reserved.

This PDF has been generated from SAGE Research Methods Cases. 


\begin{abstract}
This case study discusses an aspect of the first author's PhD research that examined gay and bisexual men's accounts of sex and diabetes. Semi-structured interviews were conducted with non-heterosexual men living with diabetes both online and face-to-face. In this case, we discuss some of the advantages and disadvantages of these two types of interviews and shed light on some of the unexpected events that occurred during data collection. We then consider how some of these incidents may relate to the interviewer's "outsider" and "insider" positions within the research and discuss how the researcher's personal similarities and differences with participants may affect research. We then turn to the sensitivities of discussing the issue of sexual difficulties with the participants and the importance of following the participants' concerns within the interview. We end by reflecting on how the research emerged both from the researchers' prior agenda and the participants' concerns. The need for caution and care when representing accounts of illness, particularly those from marginalized groups, is highlighted.
\end{abstract}

Learning Outcomes

By the end of this case, students should be able to

- Assess the pros and cons of online and face-to-face interviews

- Have a better understanding of the realities of conducting interviews

- Have an understanding of the role that researcher similarity and difference can play when conducting qualitative health research

- Better understand methodological challenges involved in conducting research with marginalized groups

- Recognize that good qualitative health research requires balancing the researchers' agenda with participants' concerns

\title{
Project Overview and Context
}

The project described here was part of the first author's PhD research, supervised by the second author, on lesbian, gay, bisexual, trans, and queer (LGBTQ) experiences of chronic illness (Jowett, 2011). The project initially developed in response to a recognition that LGBTQ health research has often been corralled into a sexual health "ghetto" (Peel \& Thomson, 2009). A flick through the index pages of most textbooks in health-related disciplines for words such as "gay" or "homosexuality" will likely reveal that such words typically appear only in chapters relating to sexual health and HIV. Furthermore, an examination of the LGBTQ health literature itself reveals a rather narrow focus on sexual health (Peel \& Thomson, 2009). This focus on HIV contributes to the erasure of other health concerns, perpetuates heteronormativity in our 
thinking about illness, and renders LGBTQ people living with other chronic illnesses invisible (Jowett, 2016; Lipton, 2004).

A major aim of the project then was to "give voice" to LGBTQ people living with other chronic conditions. Following a qualitative online survey on LGBTQ people's experiences of chronic illnesses (Jowett \& Peel, 2009), the issues raised were explored in more depth through one-toone interviews with LGBTQ people living with diabetes, specifically gay and bisexual men. Diabetes was chosen for a number of reasons, several of which were practical: it was one of the most commonly reported health conditions among the survey respondents and the condition for which the largest number of respondents indicated that they would be willing to be interviewed. In addition to inviting survey respondents to take part in an interview, a letter was also published in a Diabetes UK magazine requesting participants. Survey respondents who had indicated that they were willing to be subsequently interviewed were invited to take part in an online interview, whereas participants recruited through the diabetes magazine were interviewed face-to-face at the university, in their homes, or in a public place.

Interviewing: Online and Face-to-Face

Interviewing has been described as "a conversation with a purpose" (Burgess, 1984, p. 102), although the degree to which the interview feels like a free-flowing conversation depends, in part, on how structured the interview is. Like much qualitative research, in this project, a semistructured approach was taken with the interviews loosely guided by a schedule of questions while allowing the interview to flow relatively freely, exploring topics as and when they were introduced by the participant (Kvale, 1996). The design of the interview schedule was informed by a review of the literature and covered topics related to the management of diabetes, how diabetes affected their relationships and social life, as well as their perspective on their interactions with health professionals.

The main reasons for interviewing the survey respondents online were that, as some of the participants resided outside of the United Kingdom, interviewing online eliminated the barrier of geographical distance, it was free to use, and it was in keeping with the text-based online (and anonymous) nature of their previous participation in the survey. A more detailed discussion of using online interviews in this project can be found elsewhere (Jowett, Peel, \& Shaw, 2011); however, it is worth briefly summarizing some general advantages and disadvantages of online interviews.

\section{Advantages of Online Interviews}

- It enables the researcher to overcome barriers of distance and reach a wider geographical 
spread of participants.

- It allows participants a greater degree of anonymity which may result in less inhibited responses when studying sensitive topics.

- Using instant messaging eliminates the need for transcription of data.

\section{Disadvantages of Online Interviews}

- Participants need to have Internet access and need to have a reasonable level of (written and technological) literacy.

- They lack the audio-visual cues (e.g., facial expression, body language, tone of voice) that interviewers typically use to judge a participant's emotions and meaning.

- Typing takes longer than speaking, meaning that interviews take much longer and produce less data than traditional face-to-face interviews.

It should of course be noted that online interviews need not be text-based in the form of instant messaging. Were we conducting the research today, we would probably offer participants the option of an interview via video-calling software (e.g., Skype, FaceTime, Google Hangout) as an alternative. Although video-calling software such as Skype did exist at the time the research took place (between 2008 and 2010), its use was not nearly as widespread as it has become within only the last few years as high-speed WiFi alongside the ubiquity of camera-enabled smartphones, tablets, and laptops. Nevertheless, there are still advantages and disadvantages to consider when using audio-visual online interviews (Deakin \& Wakefield, 2014), and when conducting research with particularly stigmatized groups (e.g., drug users, sex workers), the anonymity offered by a text-based online interview, for some groups and individuals, may still be preferable (e.g., Barratt, 2012).

\section{Dealing With the Unexpected}

As Rubin and Rubin (1995) note, interviews are "wonderfully unpredictable" (p. 7), and our interviews were no different. As in any qualitative study, some interviews appeared to go more smoothly than others; Adam (who conducted the interviews) also developed a better rapport with some participants than others. Some participants were not particularly talkative and he struggled to get them to elaborate on their short responses. Some interviews were also more "eventful" than others. For instance, technological issues were experienced during both online and face-to-face interviews (e.g., losing Internet connection during an online interview and dictaphone batteries running low in a face-to-face interview) which interrupted the flow of the interaction.

Meanwhile, other unexpected incidents that occurred related more directly to the nature of this 
project in particular. For example, during one of the face-to-face interviews, a participant experienced a "hypo" (low blood sugar) half way through the interview. To begin with, this manifested itself in the participant simply being slower to answer questions until eventually he sat staring out of the window as if Adam were not there at all. As Adam does not have diabetes and had not witnessed someone experiencing hypoglycemia before, he was not quick to pick up on what was going, thinking that the participant was simply pondering on the question to begin with. Once it became clear that something was amiss, Adam asked whether the participant was okay and whether he would like a break. The participant immediately became aware that he must be "low," and after a short break, consisting of a cup of tea with a couple of biscuits, the participant was able to continue with the interview.

On another occasion, Adam was interviewing a participant in a quiet café, a location the participant had chosen, when an acquaintance of the participant entered. The participant quietly explained to Adam that he was not "out" to this person and so needed to be discrete. In response to this, Adam changed the subject of the conversation until the acquaintance was out of earshot. At times, Adam felt that incidents such as these interfered with data collection, but on reflection they also provided an additional insight into the lives of participants. It is experiences such as these that are often excluded from the write-up of research reports but capture the messy realities of conducting qualitative research (Hallowell, Lawton, \& Gregory, 2005).

Indeed, one area that is particularly shrouded in silence is the issue of sexual attraction, flirtation, and sexual advances between participants and researchers (although see Kong, Mahoney, \& Plummer, 2002; Roberts, 2014; Walby, 2010). One such incident occurred within this project when a participant became "over-friendly." To begin with, Adam tried to simply ignore the participant's flirtatious comments as he did not want to offend and hoped that if he did not respond, the participant might "take the hint." However, as the participant's overtures became more explicit, Adam needed to politely (not to mention awkwardly) decline his advances and probably brought the interview to an end earlier than might have otherwise been the case.

Although there is silence around the issue of flirtation and sexual advances within the interview situation, it is probably not that uncommon. For instance, Schwalbe and Wolkomir (2002) comment that it "probably occurs more often to female researchers than straight male researchers realize" (p. 209). Although Adam felt more embarrassed than threatened, this kind of experience highlights the need to take safety precautions when interviewing participants within their homes such as informing a supervisor or colleague of the time and location of 
interviews and arranging to call once the interview is complete. Many research institutions will also have their own lone working policies. Although we can never fully predict what might happen in an interview situation, Schwalbe and Wolkomir (2002) suggest that the likelihood of the interview becoming "sexualized" depends to some extent on who is interviewing who about what. The example they provide is particularly fitting for this project as they suggest that there is a greater potential for the interview to become sexualized when a gay man interviews other gay men about sexual behavior, as opposed to a straight man asking the same questions. Roberts (2014) similarly notes experiencing such sexual advances when trying to recruit gay men for a study in gay bars and suggests that his shared sexual identity brought with it ethical dilemmas that an outsider might not have had to confront.

On reflection, researchers should prepare themselves as much as possible for events such as these. For example, researchers conducting interviews with chronically ill participants should ensure that they are aware of how particular symptoms might manifest themselves and how best to respond. Similarly, in training PhD students and early career researchers, supervisors should ensure not only that safety precautions are in place but also that interviewers are prepared for how to respond if participants behave inappropriately. Of course, researchers will never be able to prepare themselves fully for every possible eventuality. Qualitative researchers should expect the unexpected. Nevertheless, a thorough risk assessment may help researchers to identify at least some of the possible events that could occur when collecting data with particular samples of the population. As we discuss below, the particular incidents that occurred in this study - such as not recognizing that a participant was having a "hypo" and being the subject of sexual advances-were also related to the researcher's outsider and insider positions.

\section{Outsider/Insider Statuses}

An "outsider" status refers to the ways in which the researcher is personally dissimilar to their participants, whereas "insider" status refers to ways in which the researcher personally belongs to the same group(s) as their participants (e.g., based on age, gender, sexual identity, healthstatus). Typically, researchers will hold both outsider and insider positions with regard to their participants; however, some kinds of status may be more salient for particular projects. As part of a reflexive approach to research, it can be useful to consider the researcher's outsider/insider status, particularly when conducting research with marginalized groups (Braun \& Clarke, 2013). Such positions are important to consider as they can influence each stage of the research process: from deciding on a research topic, developing an interview schedule, recruiting and communicating with participants, and making sense of what the participants say. As Hayfield and Huxley (2015) suggest, there are potential advantages and disadvantages of both insider 
and outsider positions. For example, researchers with an insider status may be more familiar with the issues that affect their participants' lives and may therefore ask questions that might not occur to an outsider. Similarly, experiential and culturally specific knowledge may aid the researcher in interpreting the participant's responses. On the contrary, the insider status of the researcher may result in a shared understanding between researcher and participant being assumed, which might lead to participants not fully articulating their point and/or the researcher failing to clarify the participant's narrative.

Adam held both "outsider" and "insider" positions in relation to his participants; unlike his participants, he did not have diabetes and was considerably younger than many of them, but as a gay man he shared their non-heterosexual status. Interestingly, the participants did not appear to expect that Adam would have diabetes, perhaps because health research tends to be conducted by those with a professional rather than experiential interest in health conditions. In addition to not recognizing a participant having a "hypo," this outsider position led some participants to feel the need to educate him about their condition. Although at the time this (frustratingly) led participants to describe the medical aspects of diabetes rather than their experience of living with the condition, in some ways this was an advantage as it allowed the participants to be positioned as the "expert" (Braun \& Clarke, 2013).

On the contrary, although Adam's insider status as a gay man may have led one participant to blur professional boundaries, it may also have helped to establish trust and facilitate rapport with participants through a sense of shared experiences (LaSala, 2003). For example, one participant specifically asked Adam whether he was "family" (by which she meant was he gay too) (Jowett et al., 2011; LaSala, 2003). This demonstrates that when asking participants to engage in a lengthy process of disclosure, the interviewer should be prepared to reciprocate to some degree before the interview begins (Kong et al., 2002). As Kong et al. (2002) note, asking lesbians and gay men to talk openly about their sexual identity in an interview "can be very much like asking them to go through another form of coming out" (p. 249). In this case, it felt to Adam that this reciprocal disclosure helped to establish a sense of empathic rapport. Once Adam confirmed his insider status, the same participant commented that "it can be a little spooky wondering if there is homophobia lurking around" (Jowett et al., 2011). This illustrates how important an insider status can be in developing trust when interviewing individuals from stigmatized groups. Had Adam not been gay it would have been even more important to be transparent about the motivations behind conducting the research to reassure them that there was no homophobic agenda and that it was being conducted by someone who could be trusted to appropriately represent their experiences. Another way in which Adam's insider status may also have been beneficial was when male participants opened up about the impact 
diabetes had on their sex lives.

\section{Talking About Sexual Problems}

Despite the researchers starting out with the aim of getting away from issues of sexual health, issues relating to sex were a reoccurring concern for the male participants. Although no direct question regarding sex or sexual dysfunction was asked during the interviews, questions such as "in what ways, if any, has diabetes affected your relationships?" commonly resulted in men's accounts about diabetes and their sex lives. Meanwhile, the same question tended to elicit talk about social support among the female participants. This may not necessarily reflect that diabetes has a greater impact on men's sex lives, but rather could indicate participants' willingness to discuss these issues with a male researcher. Had the interviewer been a woman perhaps more female participants would have raised these issues, or had Adam directly asked all participants about how diabetes affected their sex lives perhaps more women would have spoken about this. In other words, how the questions were phrased and who was asking the questions may all have influenced the kind of stories participants told.

On the contrary, potentially this was a more salient issue for the male participants. Most of the male participants discussed sex to some extent within their interviews, and it appeared to Adam that there was a common expectation among the male participants that this would be a topic of discussion during the interviews. Either way, Adam's insider positions may well have facilitated open discussion about the impact of diabetes on their sex lives and enabled smoother interaction as participants used gay slang when talking about sex.

Ringheim (1995) suggests that there are few social science research topics more difficult to study than sex, given its sensitivity. Not only is great care needed to avoid offending participants, but there are also potential risks when an interview becomes sexualized, as already discussed. Although Adam was relatively inexperienced as a PhD student, he had previously conducted qualitative research as part of his undergraduate research and for over a year as a research assistant. As academics, we often suggest to undergraduate students that it can be unwise to choose a highly sensitive topic such as interviewing people about illness experiences or about their sexual behavior (let alone both!) if they are complete novices, especially given that the level of supervision provided for undergraduate projects is often not as comprehensive as the "apprenticeship" style relationship a PhD student has with their supervisor(s).

However, within the context of this project, it was important that such topics were not out of bounds or dismissed. When such personal details were disclosed, time was given for 
participants to share their stories. For some of the participants, Adam was one of the few people with whom they had discussed their sexual problems. It has been suggested that this situation can be common in qualitative interviewing on health-related topics, in part, because of the length and depth of these interactions when compared with the typical length of health care appointments (Peel, Parry, Douglas, \& Lawton, 2006). For one participant in particular, the account of his diabetes-related erectile dysfunction dominated much of the interview as it had had a profound impact on his self-esteem and ability to form relationships. He later commented that he had taken part in the study specifically to share this story in the hope that it would be of some comfort to others in his position (Peel et al., 2006).

\section{Balancing the Agenda of the Researcher With Participants' Concerns}

Despite us starting out with our own agenda of wanting to push the LGBTQ health literature beyond sex by focusing on a condition such as diabetes, it became clear that this was an important aspect of these men's experiences. Furthermore, as Adam soon began to notice, the heteronormativity within academic and self-help literature on sex and diabetes was striking. Sex was largely only discussed in the context of erectile dysfunction as an impediment to vaginal intercourse within long-term (heterosexual) relationships. The gay and bisexual men in our study discussed issues of sex and diabetes in ways that were much broader than previously found in the literature. Our participants talked about erectile problems in the context of masturbation and casual sex, about switching roles (being the "top" or "bottom") as a response to sexual problems; they talked about experiencing "hypos" during sex and raised concerns that gay men might assume that their medication was for HIV.

This demonstrates the benefits of a semi-structured approach to interviewing that is flexible enough to allow participants' concerns to come to the fore and enable the researcher to follow up issues in sufficient detail. It also illustrates how important it is in qualitative research that the researcher does not allow their own agenda or prior assumptions to determine the outcome of research. There is value in allowing the research to be driven to a greater extent by the participants' concerns. As Potter and Hepburn (2005) point out, there are issues in qualitative interview research with researchers "flooding" the interview with their own social science agenda, concerns, and orientations. Indeed, we would agree with Potter and Hepburn that some (poor) qualitative research ends up "chasing its own tail, offering up its own agendas and categories and getting those same agendas and categories back" (p. 293) from the participants. Although we do not believe this is reason to abandon the use of interviews completely, an awareness of these concerns should lead us to guide the interview loosely and pay attention to our participants' concerns. It is also worth considering participants' reported motivations for participating directly (see Peel et al., 2006). At the same time, we think it would 
be naive to suggest that research can be done without any agenda at all, and as already mentioned, the kinds of questions we ask as interviewers undoubtedly influence the kinds of accounts produced. As qualitative researchers, we cannot simply "give voice" to our participants (Fine, 2002), but we can at least try to ensure that our agendas do not overwhelm the concerns of our participants.

When conducting research with marginalized groups on sensitive topics, the researcher not only needs to take care not to offend during the interview itself, but we also have responsibility in how we present the findings of our research. As Braun and Clarke (2013) note, the product of our research is often far removed from the "raw" data we collect as we transform our participants' words into our own story about the data. With representation comes responsibility, but there are times that we may wish to put some critical distance between ourselves and our participants' perspectives. For instance, when talking about diabetes and sex in this project, participants routinely constructed gay culture as highly sexualized and problematic; it was suggested that a sexualized gay culture exacerbated their negative experiences of sexual difficulties associated with diabetes. Adam was initially wary of these accounts as they could imply a monolithic gay culture, which is clearly an oversimplification (Flowers \& Langdridge, 2007), and could be interpreted in ways that could further stigmatize gay and bisexual communities. At the same time, it was important not to discount the participants' experiences. Being an insider again can have its advantages by sensitizing the researcher to the ethical and political issues of representing a marginalized group (Pitts \& Smith, 2007).

\section{Conclusion}

The research project described in this case aimed to "give voice" to a marginalized group whose experiences of chronic illness generally had previously been neglected within the health research literature. To do this, we drew on a number of qualitative methods including online and face-to-face semi-structured interviews. There were advantages and disadvantages of both kinds of interview (Jowett et al., 2011), and unexpected incidents occurred throughout data collection. The interviewer's "insider" status as a gay man helped to establish trust and rapport, but it also led to one participant blurring the professional boundaries of research. Although the researchers began the project with an aim to move beyond sex in LGBTQ health research, one of the papers resulting from the research focused specifically on gay and bisexual men's experiences of sex and diabetes. This arose from the concerns of the male participants themselves and from a recognition that gay and bisexual men's experiences had been neglected in this area of the diabetes literature. When conducting qualitative research on health-related topics, particularly with marginalized groups, it is important to take a reflexive 
approach, whereby the researcher recognizes their influence throughout the research process and considers carefully how they are representing those they are researching.

\section{Exercises and Discussion Questions}

1.What are the potential problems with conducting sensitive research via instant messaging?

2.In qualitative health research, to what degree is research driven by the researcher's agenda and to what degree is it driven by participant's concerns?

3.What are the disadvantages of having "outsider"/"insider" positions in relation to participants (e.g., having/not having experience of an illness you are researching), and what can be done to mitigate those disadvantages?

4.What are some of the key ethical issues when conducting research on sensitive topics with marginalized groups?

\section{Further Reading}

Dowsett, G. (2007). Researching gay men's health: The promise of qualitative methodology. In I. H. Meyer \& M. E. Northridge (Eds.), The health of sexual minorities: Public health perspectives on lesbian, gay, bisexual, and transgender populations (pp. 419-441). New York, NY: Springer.

Jowett, A. (2011). Chronic illness in non-heterosexual contexts: Towards a critical LGBTQ health psychology (Unpublished doctoral thesis). Aston University, Birmingham, UK.

Jowett, A., Peel, E., \& Shaw, R. (2011). Online interviewing in psychology: Reflections on the process. Qualitative Research in Psychology, 8, 354-369. doi:http://dx.doi.org/10.1080/14780887.2010.500352

Peel, E., Parry, O., Douglas, M., \& Lawton, J. (2006). "It's no skin off my nose": Why people take part in qualitative research. Qualitative Health Research, 16, 1335-1349.

\section{References}

Barratt, M. J. (2012). The efficacy of interviewing young drug users through online chat. Drug and Alcohol Review, 31, 566-572. http://dx.doi.org/doi:10.1111/j.1465-3362.2011.00399.x

Braun, V., \& Clarke, V. (2013). Successful qualitative research: A practical guide for beginners. London, England: SAGE.

Burgess, R. G. (1984). In the field: an introduction to field research. London, England: Unwin Hyman. 
Deakin, H., \& Wakefield, K. (2014). Skype interviewing: Reflections of two PhD researchers. Qualitative Research, 14, 603-616. doi:http://dx.doi.org/10.1177/1468794113488126

Fine, M. (2002). Disruptive voices: The possibilities for feminist research. Ann Arbor: University of Michigan Press.

Flowers, P., \& Langdridge, D. (2007). Offending the other: Deconstructing narratives of deviance and pathology. British Journal of Social Psychology, 46, 679-690. doi:http://dx.doi.org/10.1348/014466607X177713

Hallowell, N., Lawton, J. \& Gregory, S. (Eds.). (2005). Reflections on research: The realities of doing research in the social sciences. Maidenhead, UK: Open University Press.

Hayfield, N., \& Huxley, C. (2015). Insider and outsider perspectives: Reflections on researcher identities in research with lesbian and bisexual women. Qualitative Research in Psychology, 12, 91-106. doi:http://dx.doi.org/10.1080/14780887.2014.918224

Jowett, A. (2011). Chronic illness in non-heterosexual contexts: Towards a critical LGBTQ health psychology (Unpublished doctoral thesis). Aston University, Birmingham, UK.

Jowett, A. (2016). Chronic illness. In A. E. Goldberg (Ed.), The SAGE encyclopedia of LGBTQ studies (pp. 228-230). New York, NY: SAGE.

Jowett, A., \& Peel, E. (2009). Chronic illness in non-heterosexual contexts: An online survey of experiences. Feminism \& Psychology, 19, 454-474. doi:http://dx.doi.org/10.1177/0959353509342770

Jowett, A., Peel, E., \& Shaw, R. L. (2011). Online interviewing in psychology: Reflections on the process. Qualitative Research in Psychology, 8, 354-369. doi:http://dx.doi.org/10.1080/14780887.2010.500352

Jowett, A., Peel, E., \& Shaw, R. L. (2012). Sex and diabetes: A thematic analysis of gay and bisexual men's accounts. Journal of Health Psychology, 17, 409-418. doi:http://dx.doi.org/10.1177/1359105311412838

Kong, T., Mahoney, D., \& Plummer, K. (2002). Queering the interview. In J. F. Gubrium \& J. A. Holstein (Eds.), The handbook of interview research (pp. 239-257). Thousand Oaks, CA: SAGE.

Kvale, S. (1996). InterViews: An introduction to qualitative research interviewing. Los Angeles, CA: SAGE.

LaSala, M. C. (2003). When interviewing "family": Maximizing the insider advantage in the qualitative study of lesbians and gay men. In W. Meezan \& J. I. Martin (Eds.), Research 
methods with gay, lesbian, bisexual and transgender populations (pp. 15-30). New York, NY: Harrington Park Press.

Lipton, B. (2004). Gay men living with non-HIV chronic illness. Journal of Gay and Lesbian Social Services, 17, 1-23. doi:http://dx.doi.org/10.1300/J041v17n02_01

Peel, E., Parry, O., Douglas, M., \& Lawton, J. (2006). "It's no skin off my nose”: Why people take part in qualitative research. Qualitative Health Research, 16, 1335-1349.

Peel, E., \& Thomson, M. (2009). Lesbian, gay, bisexual, trans and queer health psychology: Historical development and future possibilities. Feminism \& Psychology, 19, 427-436. doi:http://dx.doi.org/10.1177/0959353509342691

Pitts, M. \& Smith, A. (Eds.). (2007). Researching the margins: Strategies for ethical and rigorous research with marginalized communities. Basingstoke, UK: Palgrave Macmillan.

Potter, J., \& Hepburn, A. (2005). Qualitative interviews in psychology: Problems and possibilities. Qualitative Research in Psychology, 2, 281-307. doi:http://dx.doi.org/10.1191/1478088705qp045oa

Ringheim, K. (1995). Ethical issues in social science research with special reference to sexual behaviour research. Social Science \& Medicine, 40, 1691-1628. doi:http://dx.doi.org/10.1016/0277-9536(94)00279-3

Roberts, S. (2014). "Out" in the field. Reflecting on the dilemmas of insider status on data collection and conducting interviews with gay men. Equality, Diversity and Inclusion: An International Journal, 33, 451-461. doi:http://dx.doi.org/10.1108/EDI-07-2013-0056

Rubin, H. J., \& Rubin, I. S. (1995). Qualitative interviewing: The art of hearing data. Thousand Oaks, CA: SAGE.

Schwalbe, M. L., \& Wolkomir, M. (2002). Interviewing men. In J. F. Gubrium \& J. A. Holstein (Eds.), The handbook of interview research (pp. 203-219). Thousand Oaks, CA: SAGE.

Walby, K. (2010). Interviews as encounters: Issues of sexuality and reflexivity when men interview men about commercial same sex relations. Qualitative Research, 10, 639-657. doi:http://dx.doi.org/10.1177/1468794110380525 